\title{
Flexibility in humans
}

Different types of $\mathrm{CD} 4^{+} \mathrm{T}$ helper $\left(\mathrm{T}_{\mathrm{H}}\right)$ cell - such as $\mathrm{T}_{\mathrm{H}} 1, \mathrm{~T}_{\mathrm{H}} 2$ and $\mathrm{T}_{\mathrm{H}} 17$ cells - protect the host against diverse classes of microorganisms through the production of distinct cytokines. These $\mathrm{T}_{\mathrm{H}}$ cell subsets were originally considered to be alternative fates of differentiating naive $\mathrm{CD} 4^{+}$ $\mathrm{T}$ cells, but $\mathrm{T}_{\mathrm{H}}$ cell plasticity has been shown recently in in vitro and animal experiments. Now, Federica Sallusto and colleagues show that there is a vast flexibility in human $\mathrm{CD} 4^{+}$ $\mathrm{T}$ cell responses, as multiple kinds of $\mathrm{T}_{\mathrm{H}}$ cells can act against a single pathogen and pathogen challenge can induce a single naive $\mathrm{T}$ cell to adopt multiple $\mathrm{T}_{\mathrm{H}}$ cell fates.

To investigate the heterogeneity of human $\mathrm{CD} 4^{+} \mathrm{T}$ cells, the authors isolated four memory $\mathrm{T}_{\mathrm{H}}$ cell subsets $\mathrm{T}_{\mathrm{H}} 1, \mathrm{~T}_{\mathrm{H}} 2, \mathrm{~T}_{\mathrm{H}} 17$ and non-conventional

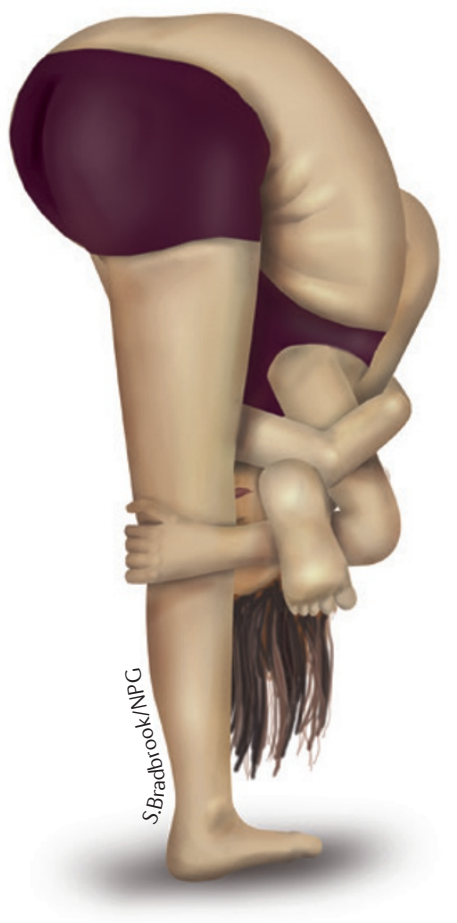

$\mathrm{T}_{\mathrm{H}} 1$ cells (which express the lineagespecifying transcription factors T-bet and retinoic acid receptor-related orphan receptor- $\gamma \mathrm{t}$ ) - from the blood of healthy donors on the basis of their chemokine receptor profiles. The $\mathrm{T}_{\mathrm{H}}$ cells were labelled with a fluorescent dye and stimulated with Candida albicans in the presence of autologous monocytes in vitro; dilution of the fluorescent dye indicated proliferation of specific $\mathrm{T}_{\mathrm{H}}$ cell subsets. Similarly to previous results, the authors found high numbers of proliferating $\mathrm{T}_{\mathrm{H}} 17$ cells and nonconventional $\mathrm{T}_{\mathrm{H}} 1$ cells, and low numbers of proliferating $\mathrm{T}_{\mathrm{H}} 1$ cells and $\mathrm{T}_{\mathrm{H}} 2$ cells in the cultures. Thus, human memory $\mathrm{CD} 4^{+} \mathrm{T}$ cells primed by C. albicans are functionally heterogeneous.

Next, the authors carried out deep sequencing to analyse the unique T cell receptor (TCR) clonotypes of antigen-specific memory $\mathrm{T}$ cells within each $\mathrm{T}_{\mathrm{H}}$ cell subset. The number of clonotypes was similar for each $\mathrm{T}_{\mathrm{H}}$ cell subset, although the frequency of antigen-specific cells in the $\mathrm{T}_{\mathrm{H}}$ cell subsets differed. Furthermore, several of the TCR clonotypes were shared between all of the $\mathrm{T}_{\mathrm{H}}$ cell subsets, and the overlap was highest between $T_{H} 17$ cells and non-conventional $\mathrm{T}_{\mathrm{H}} 1$ cells. Whereas several of the shared clonotypes had a high frequency in both $\mathrm{T}_{\mathrm{H}} 17$ cell and non-conventional $\mathrm{T}_{\mathrm{H}} 1$ cell subsets, several clonotypes were found only in one $\mathrm{T}_{\mathrm{H}}$ cell subset. Thus, C. albicansspecific memory $\mathrm{T}$ cells are highly polyclonal and include both clones that are polarized to a single fate and clones that have diversified into multiple fates.

So, is clonotype sharing a general property of memory $\mathrm{T}$ cell subsets or specific for the response to C. albicans? To address this, the authors analysed memory $\mathrm{T}$ cells specific for Mycobacterium tuberculosis or for the tetanus toxoid vaccine. The diversity of TCR clonotypes among $\mathrm{T}_{\mathrm{H}}$ cell subsets in M. tuberculosisspecific memory $\mathrm{T}$ cells was similar to that of C. albicans-specific $\mathrm{T}_{\mathrm{H}}$ cells, despite differences in proliferation. However, only very few clonotypes were shared between M. tuberculosis-specific $\mathrm{T}_{\mathrm{H}} 17$ cells and non-conventional $\mathrm{T}_{\mathrm{H}} 1$ cells. Interestingly, memory $\mathrm{T}$ cells primed by the tetanus toxoid vaccine showed similar levels of proliferation in all $\mathrm{T}_{\mathrm{H}}$ cell subsets and a high level of clonotype sharing between all $\mathrm{T}_{\mathrm{H}}$ cell subsets. Hence, the pattern and extent of clonotype sharing between different $T_{H}$ cell subsets depend on the antigen.

Finally, the authors primed highly purified naive CD4 ${ }^{+} \mathrm{T}$ cells in vitro with C. albicans to investigate whether one round of stimulation could imprint heterogeneous fates on a single naive $\mathrm{T}$ cell. Indeed, proliferating $\mathrm{CD} 4^{+} \mathrm{T}$ cell subsets produced various combinations of cytokines and not only the cytokines that are characteristic of each specific subset; that is, some interferon- $\gamma$ - and some interleukin-17 (IL-17)-sorted T cells acquired the ability to produce IL-4.

In summary, these results show that human memory $\mathrm{CD} 4^{+} \mathrm{T}$ cells primed by pathogens or vaccines are highly heterogeneous and indicate that polarized $\mathrm{T}$ cell responses result from selective expansion rather than the priming of naive $\mathrm{T}$ cell clones.

Elisabeth Kugelberg

ORIGINAL RESEARCH PAPER Becattini, S. et al. Functional heterogeneity of human memory CD4 $T$ cell clones primed by pathogens or vaccines. Science http://dx.doi.org/10.1126/science.1260668 (2014) 